\section{MENYINGKAP ENERGI ZIKIR \\ DALAM KONSEP TASAWUF SYEKH KADIRUN YAHYA}

\section{Asmal May}

Fakultas Tarbiyah dan Keguruan UIN Suska Riau

\section{Abstract}

Revealing 'Zikir' Energy In The Concept of Syekh Kadirun Yahya's Sufism: Sufism is a philosophy of life, i.e a human effort to realize moral perfection, understanding of reality nature and spiritual happiness. The journey done by the Sufi could take him to be a perfect person (insane kamil). This journey is a long process requiring a deep understanding and concentration. The Sufism aims at managing moral and purification of soul. Clean soul will be easy to be connected to God. Higher level of clean soul is closer to God. This is because the most important aim of sufism is to get closer to God. The main teaching of Syekh Kadirun Yahya's sufism is dzikr. To get closer to God, one should conduct dzikr. According to him, dzikir has an exraordinary energy and could be used for any purposes when it is conducted based on accurate method. The intension of Syekh Kadirun Yahya is that he analyzes the power of dzikr through methaphisical exacta approach. His analogy is rational and logical..

Keywords: Sufism, dzikir, metaphisika exacta, energy.

\section{Pendahuluan}

Tasawuf merupakan aliran dalam Islam yang lebih mengutamakan soal-soal extrems (intrensik) peribadatan dalam rangka mendekatkan diri kepada Tuhan. Hal ini tampak pada landasan ajaran bahwa pada hakekatnya hidup di dunia ini hanyalah untuk melaksanakan peribadatan pada Allah serta berusaha mendekatkan diri kepadaNya. Untuk mencapai hal yang demikian, para sufi menempuh suatu jalan hidup dengan bertasawuf, mistik (kerohanian). ${ }^{1}$

Tentang kehidupan kerohanian tersebut para sufi mencontoh kehidupan Rasulullah saw. sebagaimana yang ditegaskan oleh Hamka ${ }^{2}$ bahwa Nabi Muhammad Saw, disamping sebagai seorang Rasul pendiri negara, ahli siasat, pemimpin perang, terdapat juga kehidupan yang menjadi sendi semuanya itu, yaitu kehidupan kerohanian. ${ }^{3}$ Kehidupan yang demikian juga diikuti oleh para sahabat utamanya seperti: Umar bin Khatab4, sekalipun kekuasaan tertinggi sebagai khalifah ditangannya, namun semuanya itu tidaklah mengurangi nilai-nilai kehidupan kerohaniannya, demikian pula halnya Utsman bin 'Affan' serta 'Ali bin Abi Thalib'. Bahkan terhadap 'Ali dikatakan oleh Sofyan bin Uyainah bahwa' 'Ali adalah sebesar-besar sahabat Nabi

1 Harun Nasution, Islam Ditinjau Dari Berbagai Aspeknya, Jakarta, Bulan Bintang, 1974, hlm. 74.(Selanjutnya disebut Islam Ditinjau)

${ }^{2}$ Nama lengkapnya adalah Prof.Dr.H.Abdul Malik Karim Amrullah, lahir di Maninjau Sumatera Barat, wafat 24 Juli 1981 dalam usia 74 tahun. Hasil karyanya dalam berbagai bidang ilmu pengetahuan keislaman yang diterbitkan lebih dari 50 judul.

${ }^{3}$ Hamka, Tasawuf, Perkembangan dan Pemurniannya, Jakarta, Panjimas, 1984, hlm. 87-88. (Selanjutnya disebut Tasawuf).

${ }^{4}$ Umar bin Khattab r.a (40 s.H-23 H/584-644 M) dari suku Quraisy-Adawy. Khalifah kedua dari Khulafaaur-Rasyidin. Khalifah pertama yang disebut Amiriu Mukminin. Seorang sahabat mulia, pemberani, teguh dan pemenang berbagai pertempuran.

5 Utsman bin Affan r.a. (47 s.H.-35 H./577-656 M.) dari suku Quraisy, Amirul Mukminin, bergelar Dzun Nuraini, Khalifah ketiga dari KhulafaurRasyidin. Lahir di Mekkah dan dikenal sebagai tokoh kaya yang terhormat.

${ }^{6}$ Ali bin Abu Thalib r.a. (23 s.H.-40 H./600-661 M.). Beliau lahir di Mekkah, dari bani Hsyim dan suku Quraisy. Khalifah keempat dari Khulafaur-Rasyidin. Masuk dalam kategori 10 sahabat ahli surga. Sebagai putra paman Nabi saw., ia pun termasuk tokoh dan ulama besar di bidang hukum. Beliau juga dikenal sebagai tokoh pemuda pertama yang masuk Islam.

7 Nama lengkapnya adalah Sufyan ibn 'Uyainah al-Kufi al-Makky al-Hilaly, seorang tabi' tabi'in, dilhirkan di Kufah 107 H dan wafat 198 H. Ia dikenal sebagai orang imam yang 'alim, bersikap zuhud dan wara', terpercaya (sabt) dalam keilmuannya, sehingga para ulama sepakat bahwa hadits dan riwayatnya adalah sahih. 
dalam hidup zahid. Cara hidup bertasawuf ini diwarisi secara terus menerus dari setiap generasi, akhirnya terbentuklah suatu ilmu yang tersusun rapi dengan metode-metode tersendiri dan dinamakan dengan "tarekat"s

Menurut Kadirun Yahya pengamal tarekat tidak boleh mengabaikan atau meninggalkan syariat, sebab antara keduanya merupakan satu kesatuan yang tidak dapat dipisahkan. Tarekat adalah cara mengamalkan syariat dan menghayati inti daripada hakikat syariat itu sendiri serta menjauhkan diri dari hal-hal yang melalaikan pelaksanaannya serta menjauhkan diri dari hal-hal yang dilarang oleh syariat itu sendiri. Dalam melaksanakan syariat dan tarekat di tengahtengah masyarakat, harus memperhatikan adat isitadat setempat dan harus diselaraskan dengan dasar negara Pancasila dan UUD 1945.9

Lebih jauh Kadirun Yahya menjelaskan hubungan antara syariat dengan tarekat (dzikrullah) ibarat antara mobil dengan platinanya. Tanpa platina mobil tak bisa jalan, tetapi platina bukan mobil. Islam adalah keseluruhan agama yang disyariatkan oleh Allah melalui RasulNya, dan dzikrullah sebagai tenaganya. Ilustrasi lainnya adalah bawang. Kulit bawang itu sendiri sekaligus adalah isinya dari lapisan pertama sampai dengan lapisan terakhir. Kulit bawang adalah hakikat bawang itu sendiri dan sebaliknya, hakikat bawang adalah kulitnya itu sendiri. Bagitu pulalah halnya antara syariat dan tarekat, antara syariat dan hakikat. Tarekat adalah pengamalan syariat itu sendiri. Maksudnya kita harus masuk agama Islam secara keseluruhan, melaskanakan syariat dan hakikat zahir dan batin.

Tarekat itu harus berada dalam Islam, sesuai dengan al-Qur'an dan al-Hadits. Segala tarekat yang tidak sesuai dengan Islam adalah salah. Orang tarekat harus bersyariat, oleh sebab itu zaman dahulu selesai syariat dulu baru tarekat. Dengan kata lain, tarekat yang suci

8 A.J. Arberry, The Doctrin of The Sufi, London, Cambridge University Press, 1978, Hlm. 273. (Selanjutnya disebut Doctrin).

9 Ibid, hlm. 345 . harus berdiri di atas syariat yang murni. Pengamal tarekat dilarang bertarekat untuk mencari kekeramatan. Karena kalau mencari keramat, kata Kadirun Yahya sebenarnya itu merupakan pendangkalan dari kesucian Allah swt. Manusia tidak ada yang keramat, dan yang keramat itu sebenarnya hanya satu yaitu Allah swt. Sasaran orang yang bertarekat kata Kadirun Yahya ialah mencari ridha Allah semata dan memurnikan tauhid kepada-Nya. Tauhid dijadikan pola pikir, dalam bersikap Ilahi anta maksudi wa ridhaka muthlubi, dalam bertindak sesuai dengan al-'Qur'an dan al-Hadits.

Berbeda dengan tarekat lainnya, tarekat Naqsyabandiyah Kadirun Yahya mengaku pengikutnya tidak diikat oleh baiat, sumpah setia, ikrar, perjanjian dan lain sebagainya. Dalam terminologi tasawuf, tarikat berasal dari bahasa arab "thariqat"; artinya jalan, yang mengacu kepada dua makna. Pertama, makna yang asli, adalah paduan yang khas dari doktrin-doktrin, metode, dan ritual. Kedua, makna yang sering diacu, adalah organisasi yang menyatukan pengikut-pengikut jalan tertentu. ${ }^{10}$ Trimingham ${ }^{11}$ mendefenisikannya sebagai suatu metode praktis untuk menuntun (membimbing) murid secara berencana dengan jalan fikiran, perasaan, dan tindakan, dan terkendali terus menerus kepada suatu rangkaian dari tingkatan (maqamat) untuk

10 Martin Van Bruinessen, Tarekat Naqsyabandiyah di Indonesia, Bandung, 1994, hlm. 61.

11 J. Spencer Trimingham membagi perkembangan tarekat kepada tiga tahap yaitu tahap pertama (khanaqah). Pada tahap ini guru dan murid di seputarnyamereka sering berpindah-pindah - hanya berpegang pada aturan bersahaja.untuk hidup sebagaimana biasa, sampai kemudian terbentuknya tempat-tempat pemondokan pada abad kesepuluh. Tahap kedua (thariqah) pada abad ketigabelas.Masa formatif, transmisi doktrin, aturan, dan metode. Perkembangan aliran-aliran tasawuf berkesinambungan : silsilah-thariqah, berasal dari seorang yang mengalami pencerahan. Tahap ketiga (tha'ifah) abad kelima belas, transmisi persumpahan setia (baiat) di ssisi doktrin dan aturan. Tasawuf menjadi satu gerakan kerkyatan. Dasar-dasar baru dalam garis thariqah terbentuk, terjadi perc abangan ke dalam sejumlah besar "himpunan" atau "aliran" sepenuhn ya meleburkan diri ke dalam arus kulus wali. Lihat J. Spencer Trimingham, The Sufi Orders in Islam, Oxford University Press, London, Oxford, New York, 1973, hlm. 3-4. 168 
dapat merasakan hakekat yang sebenarnya. ${ }^{12}$ Pada hakekatnya ilmu tasawuf yang diwariskan oleh para sufi terdahulu, baik ajaran yang berbentuk tulisan atau berupa ucapan nasehat terhadap muridmuridnya adalah laksana mutiara yang sangat berharga. Bahkan syekh Kadirun Yahya ${ }^{13}$ berkomentar bahwa hal tersebut menggambarkan tasawuf bukanlah soal yang ringan dan mudah.

Ia dapat mendatangkan keuntungan yang sangat berharga bagi orang-orang tertentu dan dapat pula membahayakan. Ia bagaikan pedang bermata dua, dapat memotong lawan dan makan tuannya, kalau pedang tersebut berada ditangan yang tidak ahlinya, tetapi kalau berada ditangan kesatria, ia dapat melumpuhkan lawan dan dianggap keramat serta mulia. ${ }^{14}$

Para tokoh tasawuf yang telah meninggalkan warisan budaya spritual yang amat berharga itu, baik dalam bentuk karya tulis, maupun dalam bentuk lisan dan amal perbuatan sungguh banyak. Salah seorang di antara mereka ialah Kadirun Yahya, beliau termasuk salah satu tokoh tasawuf terkenal di Sumatera Utara yang mempunyai murid banyak tersebar ke berbagai Propinsi di Indonesia, bahkan sampai ke Malaysia, Singapura, Brunai Darussalam. Tasawuf yang diajarkan kepada murid-muridnya dapat dikaji ulang melalui sistim yang dinamakan tarekat naqsyabandiyah. Pengkajian tentang dzikir sering dianalogikannya dengan kajian matematika excacta. Bagaimanakah argumentasinya dalam mengimplementasikan dzikir

12 Ibid., Lihat juga Marshall G. S. Hodgson, The Venture of Islam, The University of Chicago and London, 1974, Hlm. 214. (Selanjutnya disebut The Fenture).

13 Kadirun Yahya, nama lengkapnya adalah Prof Dr. H.Sidi Syekh Kadirun Yahya, M.Sc. Pendiri dan Rektor Universitas Panca Budi di Medan, salah satu fakultasnya adalah "Fakultas Ilmu Kerohanian dan Metafisika" adalah satu-satunya di dunia. Kalau saya tidak keliru terdapat sejumlah lembaga pendidikan dengan tujuan yang serupa, tapi kalau kita tambahkan kata sifat "Islam" pada kata "dunia" dalam kalimat tadi mungkin saja ada benarnya.

11 Kadirun Yahya, Capita Selecta Tentang Agama, Methapisika, Ilmu Eksata, Medan, UNPAB, 1982, hlm. 8. melalui dalil-dalil matematika, inilah yang menjadi fokus kajian dalam makalah ini.

\section{Inti Sari Ajaran Tasawuf Syekh Kadirun Yahya}

Bagian yang termasuk inti dalam pengajaran tasawuf Syekh Kadirun Yahya adalah pengajaran zikir, yaitu agar seseorang melakukan upaya mengingat Allah atau menyebutNya (zikrullah), menunggu atau mengintip tajalli Allah( muraqabat Allah), menghadapkan hati kepada Allah (tawajjub ila Allah), dan menyaksikan tajalli Allah (musyahadat). Keempat upaya itu haruslah di wujudkan dengan tekad yang kuat, kemauan keras, menyatukan renungan, serta terus menerus mengurangi bahkan menghabiskan perhatian kepada selain Allah, semua hal itu dapat dicapai melalui zikir. Zikir lahir dan batin tanpa lalai pada setiap waktu dan tempat dengan ucapan $L a$ ilaha illallah adalah lafal zikir yang paling mulia dan itulah yang tertinggi. Karena mengingat Allah secara terus menerus jelas akan berfungsi menumbuhkan cinta kepada Allah, sehingga Allah pula mencintainya.

Kadirun Yahya menekankan penghayatan makna setiap lafal zikir tersebut, bukan sekedar mengucapkan dengan lidah, melainkan pemusatan rasa dan pikiran berhadapan dengan Allah yang harus mengalir ke dalam sekujur tubuh. Setiap kata yang keluar dari kata hati adalah menajamkan ingatan pada Allah semata-mata, dengan pengertian bahwa tak ada yang kuasa kecuali Allah, Tuhan semesta لا إله الا اله di sebut dengan zikir nafi itsbat, yaitu لע berarti menafikan (meniadakan) bahwa tak ada Tuhan yang berupa manusia, patung, batu dan lainnya kemudian إلا اله berarti mengisbatkan (menetapkan) kecuali Allah. Nafi isbat merupakan pengetahuan yang di yakini, bahwa tak ada tuhan pada sesuatu dan dalam bentuk bermacammacam, kecuali hanya Tuhan Yang Tunggal, yaitu Allah. 
Menurut Kadirun Yahya bila seseorang selalu mengingat Allah (zikrullah) niscaya Ia akan menyampaikan kepada wajah-Nya Yang Maha Mulia. Caranya ia mengingat (driker) adalah ia sebut dengan lidahnya dan ia ingat maknanya dengan hatinya, baik makna nafi (peniadaan) maupun makna istbat (penetapan). Pada makna nafi haruslah ia meniadakan hakikat kediriannya yang bersifat waham dengan menggambarkan bahwa tiada hakikat kedirian baginya sedang pada makna isbat haruslah ia menetapkan keberadaan Tuhan dalam hatinya dengan tidak menggambarkan sesuatu dalam hatinya kecuali Allah.

Selanjutnya bila seseorang mengupayakan muraqabat kepada wajah Allah, niscaya ia akan mendekatkan wajah-Nya Yang Maha Mulia. Caranya ia melakukan muraqabat haruslah : pertama, ia mengingkari hakikat wujudnya, yakni mengingkari bahwa aspek batinya bukan Tuhan (itulah makna لإله Allah SWT dalam hatinya dan itulah makna الاله Selanjutnya bila seseorang melakukan tawajjub kepada Allah SWT. niscaya ia akan menyampaikannya kepada wajab-Nya Yang Maha Penyayang. Cara tawajjuh haruslah : ia hadirkan hatinya atas ada Allah dan ia sunyikan Dia dari selubung huruf serta dari segenap makhluk. Terakhir, bila seseorang hendak melakukan musyahadat kepada wujud Allah, niscaya Ia menghimpunnya dalam wajah-Nya Yang Maha Pengasih. Cara musyahadat haruslah : setelah ia menyadari (menyaksikan) hakikat mantap dirinya yang denganNya muncul hakikat aktualnya, maka pada saat itu ia menyaksikan bayangan (nur) Tuhan dalam diri (hati/ruh/batin)nya, sebagaimana ia menyaksikan dirinya.

Kadirun Yahya juga mengingatkan agar tidak mencari dalil untuk mengetahui keberadaan Tuhan dari luar diri sendiri. Bila seseorang mencari dalil itu berarti ia butuh kepada anak-anak tangga. Bila ia mencari Tuhan bagi dirinya, dari dzat (diri/ruh )nya, niscaya ia akan menjumpainya dan mengenai itu terdapat petunjuk dari firman Tuhan yang artinya "dan pada diri kamu, tidakkah kamu melihatnya?, dari sabda Nabi Muhammad yang artinya "siapa mengenal dirinya, maka sesunggubnya ia mengenal Tubannya, dan dari kata Ali bin Abi Thalib "Cukuplah bagi anda renungan anda kepada diri anda". Seperti telah disinggung dimuka, sebenarnya "menyaksikan Tuban" (maksudnya: menyaksikan bayangan/nurnya) melalui hati (batin/ruh) itulah yang disebut juga ma'rifat Allah (mengenal Allah) atau ma'rifah hakiki (sejati) yang dicari kaum sufi.

Dari butiran lain pengajaran Kadirun Yahya juga dapat dipahami bahwa orang yang memperoleh makrifah hakiki itu sama dengan orang yang menjumpai (mengalami) malam kadar (ليلة القدر). Menurutnya, siapa yang berhasil mewujudkan amal-amal dalam rangka mendekati Tuhan, maka ia hidup bersama Allah, ia diberkati dalam usianya yang singkat dan memperoleh pada saat yang pendek karunia Tuhan tidak mungkin dapat di lukiskan dengan kata-kata. Ia diberi karunia yang membawa kepada upaya memanfaatkan waktu sebaikbaiknya (karena khawatir pada kehilangan waktu) dan segera menekuni amal-amal hati dan badan. Di tengah ketekunan itu datanglah kepadanya karunia yang tiada tara memancar kepadanya cahaya-cahaya ke Tuhanan yang tidak mungkin dapat dilukiskan dengan ungkapan bahasa. Semuanya itu berlangsung dalam waktu yang singkat. Terbukalah baginya apa yang terbuka bagi orang lain dalam seribu bulan, seperti derajat malam kadar yang beramal padanya bagi siapa yang menjumpainya, lebih baik dari beramal dalam seribu bulan (tengah malam kadar).

Dari pengajaran di atas jelas dapat dipahami bahwa kehadiran cahaya-cahaya ke Tuhanan ke dalam hati seseorang dan keterbukaan sesuatu baginya dengan nilai yang tiada tara (seperti malam kadar berbanding seribu bulan) itulah pengalaman memperoleh makrifah sejati. Hanya, orang yang telah mengalami ma'rifah sejati yang berhak dengan sebutan sang 'arif (lengkapnya: 'arif bi Allab: yakni orang yang mengenal Tuhan dengan pengenalan hakiki).

\section{Energi Dzikir dalam Tasawuf Syekh Kadirun Yahya}


Pada hakekatnya ilmu tasawuf yang diwariskan oleh para sufi terdahulu, baik ajaran yang berbentuk tulisan atau berupa ucapan nasehat terhadap murid-muridnya adalah laksana mutiara yang sangat berharga. Bahkan syekh Kadirun Yahya ${ }^{15}$ berkomentar bahwa hal tersebut menggambarkan tasawuf bukanlah soal yang ringan dan mudah. Agama Kristen, yang memang secara lebih eksklusif bersifat spritualistik, tampaknya banyak memanfaatkan fenomena yang bergejolak itu. Jauh sebelumnya, sebagian manusia modern merambah ajaran yoga dalam Budha, semedi dalam Hindu dan pertemuan antara Yang dan Yin dalam Tao.

Sementara Islam, modernis yang dominan di masa kini cenderung kering kerontang, terlalu menekankan sisi rasionalistik dan berorientasi legal formalistik. Jika Islam ingin ditawarkan untuk menarik simpati manusia modern, penekanan kepada syariat perlu diimbangi dengan penekanan kepada sufisme dinamis, realistis. Misi dakwah Islam layak mengembangkan aspek nomos oriented (syariat) dan etos oriented (thariqat) Tampaknya, ada kecendrungan untuk menarik pemikiran Islam yaitu kearah Islam yang mistik, misterius, klenik, pedukunan, tuah dan sakti dengan kedok taswuf dan thariqat. Sebagai cara mengcaunter tidak layak mengimitasi kaum modernis yang mengutuk sufisme dan ternyata gagal juga membendungnya. Sementara korbannya adalah Islam menjadi kering dan legal formalistik. Sealiran sufisme yang bersifat dinamis dikembangkan untuk memberikan alternatif cara hidup kerohanian yang progresif, optimis dan praktis bukan spritualisme eksis, statis, pessimis, eksklusif dan materialistis sebagaimana tampak kecendrungan sementara penganut sufisme masa kini.

${ }^{15}$ Kadirun Yahya, nama lengkapnya adalah Prof Dr. H.Sidi Syekh Kadirun Yahya, M.Sc. Pendiri dan Rektor Universitas Panca Budi di Medan, salah satu fakultasnya adalah "Fakultas Ilmu Kerohanian dan Metafisike" adalah satu-satunya di dunia. Kalau saya tidak keliru terdapat sejumlah lembaga pendidikan dengan tujuan yang serupa, tapi kalau kita tambahkan kata sifat "Islam" pada kata "dunia" dalam kalimat tadi mungkin saja ada benarnya.
Kebutuhan akan spiritualisme di negara-negara maju, di Amerika Serikat umpamanya, kebutuhan spiritualisme telah kuat terasa sejak tahun 1960-an. Hal itu dapat dilihat dari maraknya budaya hippies dan grandpeace, yang memberontak terhadap kemapanan yang nepotis dan korup. Mereka pun mencari alternatif baru. Ada yang positif, mereka ziarah ke India untuk belajar yoga dalam Budha dan karma dalam Hindu, yang dan yin dalama Tao dan thariqat dalam Islam, namun tidak sedikit pula yang berdampak negatif.

Times, sebuah majalah di Amerika Serikat, melaporkan adanya trend masyarakat Paman Syam itu untuk kembali kepada Tuhan. Majalah itu berdasarkan hasil polling yang dibuat menyatakan bahwa saat ini lebih banyak orang-orang A.S. yang berdoa ketimbang berolah raga, pergi ke bioskop ataupun berhubungan seks. Kecendrungan akan spirtualisme itupun makin lama makin meningkat. Memang, disamping ditandai oleh derasnya arus informasi dan dahsyanya perkembangan teknologi canggih dibidang informasi, zaman ini ternyata juga diwarnai arus baru di tengah masyarakat dunia yaitu kerinduan pada kesejukan batin dan ke dalaman sukma. Mencari inspirasi dan kebijakan dari falsafat timur dan informasi tentang persoalan inner self menjadi sesuatu yang trendy belakangan ini. Inilah mungkin yanbg diisyaratkan oleh al-Qur'an, walillahi al-masyariq wa almaghrib d ainama tuwallu fathsamma wajbu Allah, yang oleh Rudolf Ott dituangkannya dalam karya Misticism East and West, yakni pertemuan pemikiran barat yang rasional dengan kearifan dunia timur. Kearifan dunia timur itu diformulasikan oleh Mulla Shadra dalam karyanya, alHikmat al-Muta'adiyyat, (Kearifan Puncak).

Menurut Kadirun Yahya, para sufi lebih mengharapkan ilmu ilhamiyah, karena itu mereka lebih tidak tertarik untuk mempelajari buku-buku atau dalil-dalil, mereka lebih mengandalkan mujâhadah, menghindar dari sifat-sifat tercela, yang berbau duniawi dan selalu mengharapakan ridho Allah. Orang yang mendapat ridho-Nya, jelas Allah akan menguasai hati hamba-Nya. Dan menghadiahkan nur keilmuan dalam jiwanya. Karena itu para sufi berjuang keras untuk 
mendapatkan ilmu ladunni, mereka akan mengosongkan hati dan menjauhi segala yang berbau keduniaan.

Lebih jauh Kadirun Yahya mengungkapkan bahwa sungguh banyak manfaat dzikrullah jika dilakukan melalui metode yang tepat dan benar. Dzikrullah bisa mendatangkan manfaat untuk apa saja yang diinginkan pengamalnya asal kepada yang diredhai Allah. Bukti-bukti manfaat dzikrullah ini dapat diketahui dalam buku yang ditulis oleh Prof. KH. Djamaan Nur ${ }^{16}$ Untuk mendapatkan faedah zikrullah (energi zikrullah) secara maksimal, seseorang yang berdzikir harus melaksanakan adab-adab dzikir sesuai dengan metode yang diterapkan oleh syekh mursyid kepadanya. ${ }^{17}$ Sebagaimana diketahui bahwa metode dzikir yang diterapkan oleh setiap tarekat, jarang yang sama, lain tarekat lain pula metodenya. Tasawuf sangat rasional, kata Syekh Kadirun Yahya tasawuf ialah ilmu metaphysika exacta yaitu ilmu yang :

1. Membuktikan bahwa agama adalah wet-wet reel/hukum yang sempurna, yang nyata menyelamatkan hidup dan kehidupan insane dunia dan akhirat, dan yang mampu membentuk insaninsan kamil.

2. Tidak mengganggu gugat satu sarahpun soal-soal ibadat, bahkan memperkokoh ibadat dan amalan-amalan nawafil.

3. Merupakan scintifical explanation dari ayat-ayat suci al-Qur'an dan al-Hadits atas dasar ilmu exacta.

4. Menunjukkan mana yang tasawuf Islam sejati, mana pula aliran kpercayaan, kebatinan yang batil, walaupun sama-sama menggunakan ayat al-Qur'an (bandingkan manusia asal zina dengan manusia asal nikah dalam bentuk zahirnya sama.

16Baca, Djamaan Nur, Tasawnf dan Tarekat Naqsyabandiyah, Pimpinan Syekh Kadirun Yabya, Medan, USU Press, 2002. (Lampiran )Hlm. 1-23.

${ }^{17} \mathrm{Ibid}$., Hlm. 153.
5. Menerangkan masalah yang paling sulit tetapi paling pokok dan paling bernilai, yaitu bagaimana methoda menegakkan shalatul khasyi'in, atas dasar al-Qur'an dan Hadits dan ilmu exacta (melalui ilmu exacta semua masalah menjadi objektif, tidak subjektif.

Selanjutnya, kata Syekh Kadirun Yahya, Al-Qur'an merupakan wadah dari firman-firman Allah swt. yang tertulis, sedangkan ilmu exacta merupakan sunnatullah yang tak dapat ditawar lagi, sebagaimana yang diucapkan oleh mantan Menteri Agama Prof. Dr. Mukti Ali pada wisuda IAIN Medan 1978, bahwa ilmu alam adalah firman Allah yang tidak tertulis dalam al-Qur'an, dan kedua ilmu itulah yang dikawinkan pada Fakultas Metaphisika antara ilmu agama Islam yang mendalam mulai dari lapisan atas sampai lapisan bawahnya, mulai dari lapisan Ilmu Fiqih, Tauhid sampai kepada Tasawuf, dikawinkan dengan ilmu Sunnatullah, dari perpaduan yang sangat kompak itu akan lahirlah manusia-manusia yang cemerlang (Insan Kamil/khalifatullah fil ardhi). Firman Allah swt. :

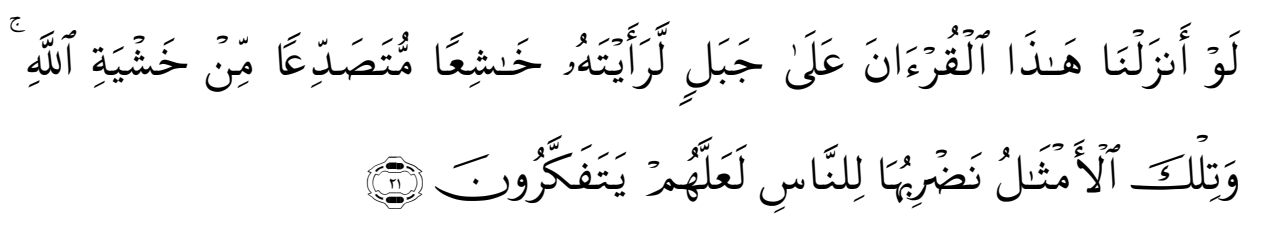

"Kalau Sekiranya Kami turunkan Al-Quran ini kepada sebuah gunung, pasti kamu akan melihatnya tunduk terpecah belah disebabkan ketakutannya kepada Allah. dan perumpamaan-perumpamaan itu Kami buat untuk manusia supaya mereka berfikir.

Menurut Syekh Kadirun Yahya, dengan analogi sebagai berikut: Kalau sarjana Phyisika menemukan tenaga-tenaga dahsyat dari elemen-elemen alam (natuur), umpama air danau dibuat waterfall yang mengeluarkan tenaga raksasa berjuta-juta volts atau tekanan-tekanan yang berjuta-juta atmosfir, hanya dengan methodic pemamfaatannya saja yang pada gilirannya dapat pula menerbitkan tenaga atom, 
nuclear, hydrogen, sinar lasser, yang dahsyat, maka hal itu parallel dengan ilmu metaphysika exacta mengungkapkan men discoverkan tenaga yang lebih dahsyat lagi yang keluar dari ayat-ayat Allah, bahkan mampu menandingi tenaga-tenaga fisik atom, nuclear dari manapun, asal pelaksanaannya dengan methodic pelaksanaan technisnya, sehingga mencapai getaran-getaran yang sebenarnya, sebagaimana yang ditegaskan dalam firman Allah sebagai berikut:

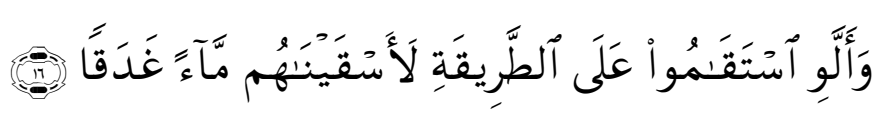

"Dan bahwasanya: Jikalau mereka tetap berjalan Lurus di atas jalan itu (agama Islam), benar-benar Kami akan memberi minum kepada mereka air yang segar (rezki yang banyak).

Terjemahan Syekh Kadirun Yahya, dan bahwanya jika mereka tetap berdiri di atas methodic yang benar niscaya akan Kami turunkan bujan (rabmat) yang lebat (nikmat yang banyak).

Menurut Syekh Kadirun Yahya bahwa tenaga fisika yang bagi kita (mortal beings) sudah begitu hebat, ternyata tak disebut-sebut Allah dalam Qur'an. Tuhan hanya menyebut tenaga al-Qur'an, itu tandanya bahwa tenaga al-Qur'an itu absolute, sedangkan tenaga fisika relative, sesuai dengan teorinya Prof. Dr. Albert Einstein dalam Relativteits Theorienya. Buktinya tuhan telah memperlihatkan dalam Qur'an betapa dahsyatnya kiamat nabi Nuh, kimat nabi Luth, Mu'jizat nabi Sulaiman, Nabi Daud melawan Goliath, nabi Isa menghidupkan orang mati, krikil batu sijjil untuk memusnahkan tentara Abrahah, nabi Ibrahim melawan Namrud, nabi Musa melawan Fir'aun dan lainlainnya.

Selanjutnya beliau menegaskan bahwa undan-undang physika itu sudah ada sejak dunia ada, tapi baru berkembang baru dibuktikan pada zaman muta'akhir sekarang ini. Sementara itu undang-undang metaphisyka sudah ada jauh sebelum dunia ada, dan pada zaman awal sudah dibuktikan oleh para nabi dan shalihin, sedangkan pada zaman modern ini seolah-olah sudah hilang bukan karena ia tidak ada lagi tapi karena tak ada lagi orang yang mengetahui rahasianya, methodenya, agar ia kembali dari alam yang tersembunyi, dengan dahsyatnya yang akan sanggup menghadapi senjata apapun dan persoalan apapun yang terjadi didunia ini.

Kata Syekh Kadirun Yahya, kehebatan kekuatan metaphysika itu ialah dapat mempertahankan dan menjamin keamanan dunia sebagaimana sabda Rasul saw. :

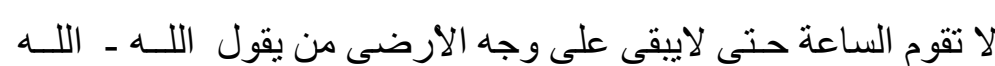

"Tiada akan datang kiamat, kecuali kalau tidak ada lagi orang yang membaca Allah, Allah, (HR. Muslim)

Menurut Syekh Kadirun Yahya, bukan negarawan yang hebathebat, atau politik mengatur dunia yang hebat, yang mampu menjamin keutuhan dunia ini, melainkan adalah tenaga metaphysika yang terbit dari kalimah Allah yang Maha Agung. Disini jelas dipahami bahwa kekuatan potensi kalimah Allah adalah maha dahsyat, sehingga mampu mempertahankan existensi dunia dari kehancuran total oleh tenaga apa pun. Ilmu yang begitu dahsyat sudah barang tentu perlu sekali kita riset dimana letak ilmiahnya the how to do nya, dari amalanamalan yang kelihatannya mubazir, seolah-olah membuang-buang waktu saja kata sebagian orang sekarang. Sebenarnya semuanya itu, akan terbukti kalau dilaksanakan dengan metode yang tepat. Semua firman Allah dan sabda Rasul itu bukan untuk orang yang tolol, tapi untuk orang yang dalam pemikirannya, salah satu contoh ucapan Rasul mengatakan :

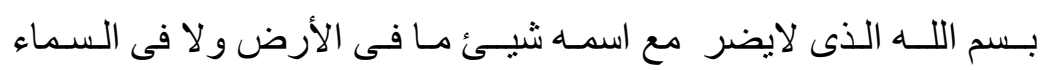

"Atas nama Allah, yang tidak memberi mudharat apa-apa yang dilangit dan di bumi ialah bagi orang yang berserta dengan naman-Nya.

Dari hadits di atas, dapat dipahami bahwa kalimah Allah, ternyata benteng yang paling kokoh untuk tempat berlindung dari segala bentuk kemudharatan. Kedua hadits di atas merupakan 178 
tantangan bagi kita untuk dapat menggunakannya dengan metode yang tepat, agar berhasil. Kata beliau, bandingkan dengan Archimides yang berhasil memusnahkan armada Xerxes raja diraja Parsi, hanya dengan berdiri di atas bukit Syracusse meng-covergeer sinar-sinar matahari dengan cermin besar berbentuk setengah bola, yang ditujukan sebagai kaca api terhadap kapal tersebut.

Hasilnya mengagumkan, seluruh armada Xerxes hangus terbakar. Begitu pulalah analog, insinyur Allah dahulu para nabi dan rasul-Nya, para wali dan shiddiqin, menghancurkan lawan-lawannya, melalui wereld ether sebagai media, bahkan lebih halus lagi yang tidak bisa ditangkap oleh radar apapun bentuknya, media yang disebut dalam ilmu tasawuf, Latifaturrabaniah.

Selanjutnya beliau mengatakan bahwa tempat berlindung satusatunya adalah dengan Allah swt. berdasarkan firmanNya sebagai berikut :

$$
\text { اعو ذ باللــهـه مـن الـشـيطـان الـر جـيم }
$$

"Aku berlindung dengan Allah dari pada Syetan yang kena rajam.

Untuk menganalisa ayat di atas, Syekh Kadirun Yahya menampilkan rumus sebagai berikut :

\section{Syetan - hantu, jin + Gandarwo + Syetan mana saja $=0$}

$\infty$ (tak terhingga $)=$ kalimah Allah

Lebih jauh dikatakan Syekh Kadirun Yahya bahwa, apabila $\infty$ tak terhingga itu palsu, tidak menggunakan metode yang benar, maka jangankan jin syetan yang lari, tapi sebaliknya kita yang habis disikatnya. ${ }^{18}$

Barangkali pada ilmu eksakta inilah sebagai salah satu dari ciri

${ }^{18}$ Seluruh argumen syekh Kadirun Yahya dikutip dari kitabnya : Capita Selecta Tentang Agama, Methapisika, Imu Eksata, Medan, UNPAB, 1982. khas metode dzikir yang diterapkan beliau menjadi semakin digemari dan menarik bagi para murid-muridnya. Beliau sering membicarakan metafisika sebagai ilmu pasti dan berusaha menjelaskan masalahmasalah keagamaan dengan contoh yang dirujuknya dari fisika. Salah satu dasar teori metafisika syekh Kadirun Yahya ialah penerapan konsep "tak terhingga" dari fisika dan matematika, seperti diatas. Kalimah Allah merupakan sesuatu yang tidak terhingga, lalu dibandingkana dengan apa saja jelas tidak ada yang menandinginya.

Selanjutnya dari metode dzikir yang benar itulah Kadirun Yahya memperoleh manfaat yang begitu besar dari kekuatan yang terkandung dalam al-Qur'an. Keajaiban yang diperolehnya sama halnya bahkan bisa dikatakan melebihi dari para wali-wali Allah yang lainnya. Hal ini diperolehnya dari kemampuan supernaturalnya. Semua keajaiban yang diperolehnya itu bukan sebenarnya karena kehebatan dia melainkan Allah lah yang hebat. Kehebatan syekh Kadirun Yahya di sini adalah karena beliau bisa dengan tepat menggunakan metode "metafisika eksakta" dan mampu menyalurkan tenaga Ilahi itu untuk apa saja yang beliau kehendaki, atau yang dikehendaki orang dari nya.

Dari uraian di atas dapat dipahami bahwa metode pendidikan dan latihan tarikat (dzikir) adalah pendalaman ilmu pengetahuan, kemudian latihan pengamalan atau dasar pengetahuan, selanjutnya seorang salik memacu diri dalam penyerahan diri secara bulat dan sempurna kepada Tuhan. Pada manfaat yang ditimbulkan oleh dzikir itu pulalah yang menjadi ciri khusus tarekat beliau, dan juga menjadi daya tarek tersendiri oleh pengikutnya. Manfaatnya secara umum adalah bahwa dzikrullah itu mengandung energi yang tiada terhingga, dan dapat dianalisa melalui pendekatan metaphisika exacta, zikir itu mampu digunakan untuk apa saja, sebagaimana yang telah dirumuskannya di atas. Misalnya untuk pengobatan, untuk menghantam musuh, jin, setan iblis hantu atau apa saja, sebagaimana pengalaman beliau dalam menumpas persoalan yang dihadapainya dimasa hidupnya. 


\section{Kesimpulan}

Berdasarkan kajian-kajian terdahulu dapat dinilai bahwa Kadirun Yahya pantas digolongkan kepada salah seorang sufi, sebab dilihat dari segi ajarannya, jelas ia memberikan penekanan makna esotoris dan kontemplasi. Ia menjelaskan secara lebih rinci teknisteknis latihan berzikir serta maqam-maqam yang harus dicapai oleh seorang salik dalam rangka mendekatkan diri kepada Tuhan, sedangkan ajaran tasawuf yang dikembangkannya adalah thariqah naqsyabandiyah, yang mu'tabarah (dapat diterima). Selanjutnya dilihat dari latar belakang perkembangan ajaran tarekat pada masanya, ternyata cukup banyak. Ketika itulah muncul tulisan-tulisan Kadirun Yahya untuk membela tarekat (khusus ajaran tarikat Naqasyabandiyah). Hal ini bisa dijadikan bukti bahwa Kadirun Yahya sebagai penganut, pengamal serta pembela dan pengembang ajaran tarikat Naqsyabandiyah bahkan sebagai salah seorang tokoh Naqsyabandiyah yang sangat vokal di Indonesia khususnya ketika itu. Akhirnya, ajaran tasawuf Kadirun Yahya yang terkandung dalam beberapa kitab yang ditulisnya (sebenarnya bukan merupakan kitab tasawuf, tetapi lebih mendekati manuskripsi ajaran tarikat Naqsyabandiyah), sebenarnya dapat dijadikan sebagai acuan bagi peminat tasawuf pada umumnya yang sangat relevan dengan pemikiran modern. Kadirun Yahya adalah seorang ulama dari kalangan Ahlus Sunnah wal Jamaah dan syekh tarikat dari golongan Asy'ariyah. Kadirun Yahya memandang ajaran Islam dari dua aspek, yakni aspek lahiriyah dan batiniyah atau aspek luar dan aspek dalam. Antara syariat dan hakikat, dipandang dan diamalkan dalam suatu kesatuan. Syariat dipandang aspek lahir, sedang hakikat sebagai aspek batin. Pendalaman dan pengamalan aspek batin lebih di tekankan tanpa melalaikan aspek lahir. Dengan kata lain, pengamalan hakikat melalui pendalaman syariat. Syariat yang dijalankan dalam tarikat, tidak lain adalah mewujudkan pelaksanaan ibadat, sedang hakikat memperlihatkan ihwal dan aspek rahasia yang terkandung di dalamnya. Cara-cara hidup yang utama ditekankan oleh Kadirun
Yahya dalam pengajarannya kepada murid-muridnya ialah kesucian batin dari segala perbuatan maksiat dengan segala bentuknya. Dorongan membuat maksiat, dipengaruhi oleh kecendrungan mengikuti keinginan hawa nafsu duniawi oleh kecendrungan keinginan memperoleh kemewahan dan kenikmatan dunia. Hawa nafsu itulah yang menjadi sebab utama dari segala perilaku yang buruk.Oleh karena itu, tahap pertama yang harus ditempuh oleh seorang murid (salik) adalah mengosongkan diri dari sikap dan perilaku yang menunjukkan kemewahan duniawi. Semua sufi sependapat bahwa dorongan hawa nafsu dibatasi dan dikendalikan untuk mencapai kesucian batin. Ajaran tasawuf Kadirun Yahya menempuh cara-cara moderat. Kehidupan di dunia ini bukan harus ditinggalkan dan hawa nafsu bukan harus di matikan, melainkan hidup ini harus dimanfaatkan guna menuju Tuhan. Gejolak hawa nafsu dikuasai melalui tata tertib hidup, disiplin diri, dan penguasaan diri, atas dasar orientasi ke Tuhanan yang senantiasa melingkupi kehidupan manusia. Hidup selalu waspada, menempatkan segala sesuatu menurut apa adanya, tidak membenci dunia dan tidak pula dijadikan sebagai jembatan kemewahan yang menampilkan kebanggaan materil. Hidup ini, bukan hanya untuk menciptakan keseimbangan antara duniawi dan ukhrawi, melainkan ini harus dikandungi cita-cita dan tujuan hidup menuju pencapaian anugerah Tuhan.

\section{Bibliografi}

Abd al-Karim al-Jilli, Al-Insan al-Kamil fi ma'rifah al-awakbir wa al-awail, Jus I, Dar al-Fikr, Beirut, 1975.

Abu Nasr al-Sarraj al-tusi, Al-luma', Dar al-Kutub al-Hadisah, Mesir, 1960.

Abul Wafa'al-Taftazani, Madkhal Ila Tasawuf al-Islam,Dar Al-saqafah Li al-Tiba'ah wa al-Nasyr,cairo, 1979.

Aboebakar Atjeh, Pengantar Sejarah sufi \& Tasawuf, Ramadhani, Solo,1994. 
A.J. Arberry, Sufism, An Account of The Mystics of Islam,Unwin Paper backs, London, 1979.

Annemarie Schimmel, Dimensi Mistik Dalam Islam, penerjemah Sapardi Djoko Damono, et.al., Pustaka Firdaus, jakarta, 1986.

B. Lewis, et.al (Eds.), The Encyclopedia of Islam, vol. III, E.J. Brill, Leiden, 1971.

Bertrand Russell, Mysticim and Logic, the Modern Library, New York, 1927.

Djama'an Nur, Tasawuf dan Tarekat Naqsyabandiyah, Syekh Kadirun Yabya, Medan, USU, 2002.

Harun Nasutioan, falsafat \& Mistisime dalam Islam, Bulan Bintang, Jakarta, 1973.

Hamka, Tasawnf, Perkembangan dan Pemurnianya, Pustaka Panjimas, Jakarta, 1984.

Hasan Ibrahim Hasan, Tarikh Al- Islam, I, Maktab al-Nahdah alMisriah, cairo, 1979.

Hasbi Ash-Shiddieqy, Sejarah dan Pengantar Ilmu Hadis, Bulan Bintang, Jakarta, 1977.

Ibn'Arabi, Fusus Albikam, edisi syekh Abd Razaq al-Kasyani, Mustafa al-babi al-Halabi wa auladih, Cairo,t.t.

Ibrahim Madkur, Fi al-Filsafat Al-Islamiyah, I, Dar al-Ma’arif, Cairo, 1976.

Ibrahim Hilal, Al-Tasawnf Al-Islami Baina al-Falsafah, Dar Nahdiah al'Arabiah, Cairo, 1979.

Imam al- Gazali, Mukasyafah al- qulub, abdul Hamid Ahmad Hanafi, Cairo, t.t.

James Hastings, ED.,"Mysticism" dalam encylopaedia of relegion and ethics, vol. IX, Charles scribner's. New York, t.t.
Jalaluddin, Pertabanan Tarekat Naqsyabandiyah, Bukittinggi, 1976.

------ Rahasia Syariat dan Tarekat, Medan, UNPAB, 1976.

J. Spencer Trimingham, The Sufi Orders in Islam, Oxford University Press, London, 1973.

Khan Sahib Khaja Khan, Studies in Tasawuf, darah-i Adabiyat-i, New Delhi,1978.

Kadirun Yahya, Capita Selecta Tentang Agama, Methapisika, Ilmu Eksata, Medan, UNPAB, 1982.

Luthfi 'Abd Badi, Islam Fi Isbaniya, al-Nahdah al-misriyah, Cairo, 1996.

Moh. Saifullah Al-Aziz, Risalah Memahami Ilmu Tasamuf, Surabaya, Terbit Terang, 1998.

Martin Van Brinesseen, Tarekat Nawsyabandiyah di Indonesia, Mizan, Bandung, 1994.

Moh. Amin al-Kurdi, Tanwir Qulub, Kairo, Tp., 1929.

Muhammad al-Gazali, khuluq al-Muslim, Dar al-Bayan, Kuwait, 1970.

Muhammad Jalal Syarif, Al- tasawnf Al-islami wamadarisubu, DarMatba'ah Al- Jamiah, Iskandariah, 1974.

Nurcholis Madjid, "Pasantern dan Tasawuf", Pesantren dan Pembangunan, LP3ES, Jakarta, 1985.

R. A. Nicholson, The Mistik Of Islam, Routledge and Kegan Paul, London, 1974.

....... Studies in Islamic Mysticim, University Press, London, 1921.

........ Fi al-Tasawnf al-Islami wal Tharikbibi, diarabkan oleh Abu al'Ala Afifi, Matbah'ah Lajnah al-Ta'lif wa al-Tarjamah wa alNasyr, Cairo, 1969.

Siregar, A. Rivay, Tasawnf, Dari Sufistik Klasike ke Neo Sufisme, Jakarta: Raja Grafindo Persada, 2002. 
Asmal May, Menyingkap Energi Zikir dalam Konsep Tasawnf...

Simuh, Tasawnf dan Perkembangannya dalam Islam, Jakarta: Raja Grafindo Persada, 1997.

Schimmel, Annemarie. Dimensi Mistik Dalam Islam, Jakarta: Pustaka Firdaus, 1986.

Solihin, KamusTasawnf, Pengantar: Ahmad Tafsir, PT Remaja Rosdakarya, Bandung, 2002.

Sayyid Husein Nasr, Tasawuf Dulu dan Sekarang, Penerjemah Abdul Hadi WM., Pustaka Firdaus, Jakarta, 1991.

Titus Burckhard, An Introduction to Sufi Doctrine, Translated By D.M. Matheson, SH. Muhammad Asharf, Lahore, 1973.

William James, TheV arieties of Religious Experience, The New American Library, New York, 1958.

Zahri, Mustafa, Kunci Memahami Ilmu Tasawuf, Surabaya: Bina Ilmu, 1995. 